\title{
O (im)possível e necessário testemunho do louco infrator
}

\section{The (im)possible and necessary testimony of the insane offender}

\author{
Marcele de Freitas Emerim* \\ Universidade Federal de Santa Catarina - UFSC, Florianópolis, Santa Catarina, \\ Brasil
}

\section{Mériti de Souza**}

Universidade Federal de Santa Catarina - UFSC, Florianópolis, Santa Catarina, Brasil

\begin{abstract}
RESUMO
Neste artigo objetivamos problematizar o testemunho e suas relações com a experiência do denominado louco infrator entendido como a pessoa que se encontra internada em medida de segurança nos Hospitais de Custódia e Tratamento Psiquiátrico - HCTPs. Apresentamos algumas das condições de emergência dos HCTPs no Brasil explicitando suas convergências e divergências no tocante à crítica ao regime tutelar. Utilizamos os aportes teóricos de Foucault, Derrida e Agamben, para trabalhar a desqualificação e a interdição do discurso do louco infrator, assim como as suas atribuições de vida nua e de vida não sacrificável. Apontam-se as condições de possibilidade à constituição do testemunho como assunção do discurso do denominado louco infrator.
\end{abstract}

Palavras-chave: Testemunho, Louco infrator, HCTPs, Foucault, Derrida.

\begin{abstract}
The aim of this article is to observe the so-called "insane offenders", namely the internals for security reasons in one of Brazilian's HCTPs - Portuguese acronym for Custody and Psychiatric Treatment Hospitals - and to retrieve their testimonies and their experiences. In it we describe Brazil's HCTP emergency sector's working conditions and their similarities and divergences when it comes to the criticism of legal guardianship system. We rely on the theoretical framework of Foucault, Derrida and Agamben to discuss the ways by which insane offenders have been denied a speech and considered to lead bare, non-expendable lives. We point out to the conditions that must be matched in order to retrieve insane offenders' testimonies and thus validate their speech.
\end{abstract}

Keywords: Testimony, Insane offender, Custody hospital, HCTPs, Foucault, Derrida.

\section{I ntrodução}


A partir dos 1990 no Brasil, o processo de redução de leitos psiquiátricos, assim como o processo de desinstitucionalização de pessoas com longo tempo de internação em hospitais psiquiátricos, tornou-se política pública amparada pelo movimento da Reforma Psiquiátrica - processo histórico, político e social que abarca transformações de práticas, saberes e valores, envolvendo instituições, serviços e relações interpessoais. Após a assinatura da Lei no 10.216, que “Dispõe sobre a proteção e os direitos das pessoas com transtornos mentais e redireciona o modelo assistencial em saúde mental" (BRASIL, 2001), vêm sendo implantados programas e serviços procurando manter e fortalecer os laços sociais dessas pessoas com seus familiares e a sociedade em geral. Entre esses programas e serviços podemos citar: as residências terapêuticas; 0 Programa Volta para Casa; o auxílio-reabilitação psicossocial; os Centros de Atenção Psicossocial - CAPS -, importante dispositivo que tem como função primordial o acolhimento às pessoas em sofrimento psíquico.

As ações observadas no Brasil no tocante à atenção à saúde mental e ao processo de desinstitucionalização fomentado pela assinatura da Lei $n^{\circ} 10.216$ muito pouco têm chegado aos Hospitais de Custódia e Tratamento Psiquiátrico - HCTPS (comumente chamados de manicômios judiciários, nomenclatura oficial até 1984). Tais instituições são destinadas ao abrigo de pessoas submetidas à medida de segurança - os considerados inimputáveis, pessoas consideradas incapazes de entender o caráter ilícito de seu ato devido a alguma doença mental. "É isento de pena o agente que, por doença mental ou desenvolvimento mental incompleto ou retardado, era, ao tempo da ação ou da omissão, inteiramente incapaz de entender o caráter ilícito do fato ou de determinar-se de acordo com esse entendimento." (BRASIL, 1984), diz o texto do Art. 26 da Lei $\mathrm{n}$ ㅇ 7.209, de julho de 1984. Diante de uma infração, tendo sido confirmada por laudo psiquiátrico a incapacidade de entendimento do infrator, o juiz considerará esse indivíduo como inimputável e, ao invés de aplicar a pena direcionada aos imputáveis (pessoas capazes de responder por seus atos), aplicará medida de segurança. Essa medida consiste na internação em HCTPs, levando em conta não a culpabilidade, como no caso dos imputáveis, mas a periculosidade, o possível retorno à prática de crime (PERES; NERY FILHO, 2002).

A medida de segurança passa a "ser um controle, não tanto sobre se o que fizeram os indivíduos está em conformidade ou não com a lei, mas ao nível do que podem fazer, do que estão sujeitos a fazer, do que estão na iminência de fazer." (FOUCAULT, 1996, p.85). Todas as possibilidades de expressão do considerado louco são reduzidas a um comportamento agressivo e violento, e não é lhe ofertada a possibilidade de defesa, de elucidação de seu ato transgressor (BARROS, 1994), e a essa pessoa, em muitos casos só resta como 
destino a internação compulsória em HCTPs - por vezes por tempo indeterminado, chegando à prisão perpétua - ultrapassando os trinta anos, tempo máximo de pena aplicado aos imputáveis, ferindo o princípio constitucional de "Todos são iguais perante a lei." (BRASIL, 1988, p.15). A crença na "periculosidade presumida" do louco infrator, atestada nos laudos psiquiátricos, tem justificado a utilização do expediente da medida de segurança.

O primeiro manicômio judiciário no Brasil foi inaugurado no Rio de Janeiro em 1921 atendendo à demanda social por uma "prisão de caráter especial". (CARRARA, 1998). Atualmente, existem 19 instituições como essa em funcionamento no país, abrigando cerca de 4000 pessoas (BRASIL, 2002). Os muros dessa instituição total (GOFFMAN, 2005) abrigam a ambiguidade dessa figura representativa de dois fantasmas do imaginário ocidental: o louco e o criminoso, assim como a ambiguidade da instituição: ora hospital de tratamento, ora prisão. Cabe ao médico especialista, o "conselheiro da punição", dizer sobre a periculosidade do infrator: o laudo psiquiátrico concede aos expedientes punitivos poder sobre as infrações e sobre os indivíduos - quem são, o que fizeram e o que podem vir a fazer - conforme aponta Foucault (2002), e cabe ao J uiz de Direito a determinação de cumprimento de medida de segurança. Os muros dos HCTP abrigam, também, conflitos de competências e saberes entre Justiça e Saúde.

O outro, compreendido como o diverso em contraponto a suposta unidade identitária do eu e do sujeito, emerge com força e eloquência nos discursos oficiais da Psiquiatria e do Direito. O outro constituído como infrator e louco é desqualificado na sua condição de cidadania e de sujeito racional. Ele também perde a possibilidade de enunciar seu discurso e de falar sobre suas experiências sendo reduzido à condição de avesso que sustenta a ilusão do sujeito cognoscente como parâmetro a priori para o sujeito moderno. A dupla inscrição da infração e da perda da razão produz uma específica ordem de experiência e de discurso por parte do denominado louco infrator. Esse cenário incita a problematizar as condições de emergência dos HCTPs e suas relações com as redes sociais que possibilitam a interdição e a desqualificação do discurso do louco infrator, bem como, as suas atribuições de vida nua e de vida não sacrificável. Pergunta-se: qual a possibilidade de enunciação dessa experiência e do discurso sobre ela no contexto e no cenário que os desqualificam? O testemunho pode abrir brechas para a emergência do discurso do louco infrator?

\section{Bio-poder, vida nua, experiência e testemunho}


A partir do século XVII desenvolveram-se duas formas de poder sobre a vida, formas estas não contraditórias entre si, porém, situadas como "dois pólos de desenvolvimento interligados por todo um feixe intermediário de relações" (FOUCAULT, 1999, p. 131). O poder disciplinar sobre os corpos encontra-se em um dos pólos, no outro há o poder sobre o "corpo-espécie, [...] transpassado pela mecânica do ser vivo e como suporte dos processos biológicos" (FOUCAULT, 1999, p. 131). Assim, além da existência de micropoderes disciplinadores junto a instituições como escolas, hospitais ou prisões, que administram os corpos dos indivíduos, que regram comportamentos - poder disciplinar; os escritos de Foucault também conduzem à identificação de um poder sobre a vida - um bio-poder.

A organização dessa forma de poder se dá a partir da "docilização dos corpos" e do gerenciamento da vida da população - há o encontro da "anátomo-política do corpo" com a "bio-política da população" (FOUCAULT, 1999). A sociedade disciplinar acontece na disciplinarização dos corpos no sentido legal, físico, moral, político, administrativo e, paralelamente, criaram-se saberes sobre os indivíduos. O poder soberano, "o direito de vida e morte" (FOUCAULT, 1999 , p. 127), a partir do século XIX passou a ser não apenas um poder de matar, mas também um poder de gerenciar a vida.

Pensando-se sob a ótica do bio-poder, a questão das medidas de segurança e do ato de trancafiar a pessoa denominada como louco infrator em um Hospital de Custódia e Tratamento Psiquiátrico HCTP -, de forma muitas vezes perpétua, deixa de estar situada apenas no âmbito disciplinar. A partir dessa ótica essas questões se associam a democracia presente nas redes sociais contemporâneas que tem a vida no centro de sua política e colocam uma linha a partir da qual a vida deixa de ser politicamente relevante, podendo ser eliminada. A morte simbólica daquele que foi submetido à medida de segurança, ao ser banido da vida em sociedade, garantiria a segurança dos demais (poder disciplinar), mas também garantiria a existência de um corpo social saudável (bio-poder). "A morte do outro não é simplesmente a minha vida, na medida em que seria minha segurança pessoal; a morte do outro, a morte da raça ruim, da raça inferior (ou do degenerado, ou do anormal), é o que vai deixar a vida em geral mais sadia; mais sadia e mais pura" (FOUCAULT, 1997, p. 305).

Inspirado na obra de Foucault (1996, 1997, 1999, 2002), e também na de pensadores como Arendt (1989) e Benjamin (1994), Giorgio Agamben trabalha o conceito de estado de exceção:

A exceção é uma espécie de exclusão. Ela é um caso singular, que é excluído da norma geral. Mas o que caracteriza propriamente a exceção é que aquilo que é 
excluído não está, por causa disto, absolutamente fora de relação com a norma; ao contrário, esta se mantém com aquela na forma da suspensão. A norma se aplica à exceção desaplicando-se, retirando-se desta. O estado de exceção não é, portanto, o caos que precede a ordem, mas a situação que resulta da sua suspensão. Neste sentido, a exceção é verdadeiramente, segundo o étimo, capturada fora (excapere) e não simplesmente excluída (AGAMBEN, 2007, p. 25).

O ordenamento jurídico estabelece uma situação paradoxal na qual o próprio ordenamento perderia validade, como nos estados de necessidade. Assim, em casos excepcionais, o soberano pode deixar de lado os direitos e garantias fundamentais para aplicar a lei que julgar mais adequada em virtude da necessidade.

Nos estados modernos, em especial no século $X X$, a necessidade foi sendo construída como mais urgente, diária, fazendo da exceção a regra. Se o estado moderno é um estado de exceção, o soberano tem o poder de usar a morte para gerir a vida. A vida do súdito deixa de ser uma vida política (bio-política), repleta de direitos, para, em virtude da exceção, ser uma vida nua, desprovida deles. O homem assume, segundo Agamben (2007), o caráter de homo sacer - vida matável e insacrificável. Matável porque pode ser morta sem que seja considerado homicídio e insacrificável porque tal morte não se constitui um sacrifício - a ela não é dado o direito do rito sacrificial. Nessa perspectiva, essa "vida nua" daria constituição aos estados modernos, estados de exceção, estruturas de bando.

$\mathrm{O}$ bando é o agrupamento de vidas submetidas ao poder soberano e que the dá validade, que the constitui enquanto poder (AGAMBEN, 2007). O soberano, ao excluir alguma vida do bando, definindo o que deve viver e o que deve morrer, cria, dá validade à própria estrutura de bando. Alguém banido, como nos campos de concentração (exemplo utilizado por Agamben, 2007), é um "fora", um abandonado, que está, paradoxalmente, o tempo inteiro sob o domínio da lei soberana. "Aquilo que nele é excluído, é, segundo o significado etimológico do termo exceção, capturado fora, incluído através de sua própria exclusão" (AGAMBEN, 2007, p. 177).

Os campos de concentração, os atos de eugenia e a eutanásia, praticados pelo Terceiro Reich, o confinamento de presos políticos em Guantánamo, são alguns dos exemplos utilizados por Agamben para relacionar o poder sobre a vida nua com a constituição dos estados que, no século $X X$, fazem da exceção a regra. A exceção, 0 abandono, o capturar fora, é exatamente a condição de existência desse estado, desse corpo social.

Aceitando-se a reflexão de Agamben e buscando-se aplicá-la ao caso das medidas de segurança e das internações nos HCTPs, pode-se dizer que com a exclusão do louco infrator da convivência social, 
almeja-se não apenas a segurança da sociedade, mas a sua própria constituição enquanto corpo bio-político saudável. A figura ambígua do louco infrator - ora doente mental, ora criminoso - sob a tutela da justiça e o discurso da psiquiatria, "condenada" a um duplo estigma, pode ser concebida como o homo sacer - banido do mundo dos homens e do mundo dos deuses (AGAMBEN, 2007).

O HCTP, como toda prisão, segue existindo (a despeito da Lei no $10.216 / 2001$, a "Lei da Reforma Psiquiátrica") como mais um expediente de proteção da sociedade contra aqueles que oferecem perigo aos demais. Além disso, é o corte realizado pelo diagnóstico da "doença mental perigosa" que parece dar condições de existência a uma sociedade pretensamente sã e pacífica. Uns precisam/devem "morrer" para que outros vivam.

O discurso oficial que anuncia e supostamente legitima o lugar atribuído ao louco infrator também destitui a sua condição de falar sobre sua experiência, sobre sua vida e seu sofrimento. A possibilidade de enunciação do testemunho proferido pelo denominado louco infrator, na medida em que a fala sobre sua experiência - com esse lugar e a partir desse lugar - encontra-se, geralmente, interditada e desqualificada.

No meio jurídico, de forma geral, o conceito de testemunho está relacionado com a noção de testis: a testemunha como um terceiro que frente a um tribunal daria a sua versão dos fatos. Mas é possível outra etimologia para a palavra testemunha: superstes - aquele que viveu algo e pode, dessa forma, dar seu testemunho (SELIGMANNSILVA, 2001; AGAMBEN, 2008). O que pode testemunhar, como superstes, o louco infrator sobre o que lhe aconteceu? Que outras falas podem ser incorporadas às discussões sobre a figura do louco infrator para além da chancela de "perigoso", proclamada historicamente pelos discursos psiquiátricos e jurídicos? Para além de uma patologia diagnosticada e comprimida em um código da Classificação Internacional de Doenças - CID 10 e de uma sentença judicial, apoiada em códigos universais que classificam uma pessoa como louco infrator, essa pessoa pode acrescentar à série de discursos construídos sobre ela outro discurso, outra fala, outro testemunho.

Além das diferenças etimológicas encontradas em testemunha "de dentro" (superstes) ou "de fora" (testis), outros entendimentos podem ser feitos a partir das noções e dos conceitos atrelados à expressão testemunho. Nas últimas décadas, o termo testemunho vem sendo utilizado na teoria literária tanto no sentido de Zeugnis (tradição europeia) como de testimonio (utilizado na América Latina), como aponta Seligmann-Silva (2001). O Zeugnis (testemunho em alemão) refere-se mais especificamente ao trabalho de memória em torno da Segunda Guerra Mundial, em especial do assassinato em massa de judeus. Tal testemunho caracteriza-se pela singularidade 
que carrega, surge a partir do ponto de vista subjetivo e prioriza a perspectiva de quem conta o que viveu. O testemunho é entendido também como "um momento de perlaboração do passado traumático" (SELIGMANN-SILVA, 2001, p. 124), para além de servir como um documento histórico. Por sua vez, o testimonio latinoamericano tem se ocupado de questões relacionadas às ditaduras militares, bem como à exploração e à repressão às minorias, e busca um registro da história. A verdade e a utilidade dos testemunhos são primordiais no testimonio. Em tal entendimento de testemunho a ênfase está no coletivo, tem a finalidade de agrupar pessoas em torno de uma mesma causa - como se fosse possível alcançar a verdade a partir de cada testemunho da experiência pessoal.

A fala do louco infrator - desqualificada, sem lugar - não é lugar da verdade, como nenhum discurso o é. Não há relação imediata entre palavras e coisas, uma única narrativa não dá conta de uma experiência - ela já é uma interpretação (SCOTT, 1999). Abre-se mão da crença de que a experiência e o testemunho dela carreguem consigo a verdade, há uma busca por "legitimidade na autoridade da experiência" (SCOTT, 1999, p. 24).

Se a experiência vivida não é garantia de verdade, tampouco são os discursos científicos os "mais verdadeiros", como a Modernidade faz crer: observa-se a sobrevalorização do logos em detrimento da experiência, a crença na transparência dos discursos científicos. É importante que mais um discurso possa ser inserido na série de discursos já existentes, que a experiência relatada pelo louco infrator seja mais um discurso (im)possível, assim como o jurídico e o psiquiátrico - falas existentes e já bem delimitadas sobre o crime e a loucura. É necessário que o louco infrator, figura banida do mundo dos direitos e que tem seu discurso desqualificado em várias instâncias, possa dar seu Zeugnis, sem a pretensão de sobrepor sua fala às demais já estabelecidas ou de considerá-la "a verdade sobre os fatos", como superstes: alguém que pode falar de algo que viveu/vive, de sua experiência singular.

Entendendo-se que a psiquiatria e o direito encontram-se, em grande medida, atrelados ao enunciado de que o sujeito da razão e da ética tem seu discurso, sua condição humana e de cidadania reconhecidos, compreende-se que o discurso do louco infrator tanto perde sua condição racional e ética quanto a possibilidade de falar sobre sua experiência e sua subjetividade. Tal testemunho pode abrir brechas nesse enunciado e apontar a contrapartida de que os binarismos razão e desrazão, loucura e sanidade, pouco servem para compreender a condição humana e muito contribuem para sustentar o pressuposto da disjunção e manter relações de poder e de hierarquia. O discurso concebido como testemunho pode abrir espaços no suposto enunciado de verdade arquitetado pela 
psiquiatria e pelo direito e oferecer possibilidades à enunciação da experiência do louco infrator.

\title{
3 E ainda... (o que resta)
}

Os campos de concentração e extermínio renderam outras reflexões a Agamben, já que ele os considera o paradigma, a norma do espaço político contemporâneo, balizado pela dinâmica do estado de exceção. Em O que resta de Auschwitz, Agamben coloca a questão do testemunho como fundamento de uma nova ética e se propõe a ler alguns desses relatos testemunhais, em especial os de Primo Levi químico e escritor italiano, sobrevivente de Auschwitz. O resto, conforme elucida Gagnebin na apresentação do livro de Agamben (2008, p. 11), é "aquilo que, no testemunho, solapa a própria eficácia do dizer e, por isso mesmo, institui a verdade de sua fala". Não se trata de algo que ainda resta dizer, tentando preencher as falhas da memória, mas de uma lacuna constitutiva da própria estrutura do testemunho.

Mesmo o testemunho daquele que viveu e sobreviveu (superstes) é colocado em xeque. Primo Levi, apresentado por Agamben (2008), questiona-se, afirmando não serem eles - os sobreviventes - as autênticas testemunhas, já que por algum motivo, "por prevaricação, habilidade ou sorte" (LEVI apud AGAMBEN, 2008, p. 42), não tocaram o fundo, sobreviveram.

Nesse paradoxo instalado pela própria testemunha sobrevivente, ela não pode dizer por que o que "merece ser dito" pertence ao que não existe mais, ao que morreu.

\begin{abstract}
A testemunha comumente testemunha a favor da verdade e da justiça, e delas a sua palavra extrai consistência e plenitude. Nesse caso, porém, o testemunho vale essencialmente por aquilo que lhe falta; contém, no seu centro, algo intestemunhável, que destitui a autoridade dos sobreviventes. As "verdadeiras" testemunhas, as "testemunhas integrais" são as que não testemunharam, nem teriam podido fazê-lo. São os que tocaram o fundo, os muçulmanos, os submersos. Os sobreviventes, como pseudotestemunhas, falam em seu lugar, por delegação: testemunham sobre um testemunho que falta. [...] Quem assume para si o ônus de testemunhar por eles, sabe que deve testemunhar pela impossibilidade de testemunhar. Isso, porém, altera de modo definitivo o valor do testemunho, obrigando a buscar o sentido em uma zona imprevista (AGAMBEN, 2008, p. 43).
\end{abstract}

Este aspecto contraditório do testemunho dos judeus sobreviventes aos campos é o que ora deseja-se relacionar ao testemunho do louco 
infrator, utilizando essa estratégia também para problematizar a supremacia do discurso jurídico e do psiquiátrico, bem como balizar uma discussão ética que problematize a clausura da razão e da norma, questionando a hegemonia do logos.

O louco está fora da razão e da norma, ele é capturado fora, a bandonado. Considerando-se a fala de Jacques Derrida em Força de Lei (2007), o louco infrator sofre "violência de língua", a violência da universalização da norma. A medida de segurança fala a língua do direito, que, por sua vez, utiliza-se da lógica jurídica, universal aplicável a todos. A língua da psiquiatria auxilia (ou até mesmo define) a sentença aplicável a alguém que não a entende. É que direito e violência andam juntos, como demonstrou Derrida no mesmo texto. A força que está na aplicabilidade da lei implica em violência. E o direito, como relembra Agamben (2008), não tende ao estabelecimento da justiça, ou da verdade. O direito busca o julgamento, a coisa julgada, juris dictum, dizer o direito. E como dizer na língua do louco infrator? Qual é a língua da loucura?

As reflexões propostas demandam o acolhimento do testemunho do louco infrator, aceitando como discurso válido já que ele é o sobrevivente do momento da infração (ou da loucura). Mas o conceito de resto como o indizível toma força aqui para se debater com a impossibilidade desse testemunho. Ainda na esteira da reflexão de Agamben e do testemunho de Primo Levi, só poderia testemunhar aquele que viveu a radicalidade da experiência dos campos de concentração, ou seja, o único testemunho possível, válido, seria o daquele que experimentou a morte, daquele que está impossibilitado de testemunhar.

Insistindo-se na problematização entre o testemunho do louco infrator e o testemunho do sobrevivente aos campos de extermínio, faz-se necessário aqui ater-se a essa impossibilidade do testemunho, ao lado da sua premente necessidade, ou melhor, da necessidade de seu acolhimento enquanto proposta ética.

Tomemos o momento da infração como o instante sobre o qual incidem as reflexões acerca da possibilidade e necessidade do acolhimento do testemunho do louco infrator. A própria lei elege tal instante como tentativa de definir se, naquele tempo, o infrator tinha capacidade de entender o caráter ilícito de seu ato. Por um lado, quanto maior o comprometimento do infrator com a loucura, em princípio maior sua capacidade de testemunhar sobre a radicalidade de seu ato. Entretanto, menor será sua capacidade de emitir testemunho racional no sentido de logicamente organizado. Por outro lado, quanto maior sua capacidade de testemunhar de maneira lógica e possível de elaboração discursiva, mais longe estará da integralidade daquele que "tocou o fundo".

Essa aporia lógica é que está no cerne de todo o testemunho e se estende ao do louco infrator. Quanto mais lúcido (luzes, iluminismo, 
razão, logos) o discurso do infrator, menos ele é louco, menor sua capacidade de testemunhar a loucura. O testemunho lógico do louco é aquilo que sobrevive à loucura e dá conta desse discurso organizado. Mas ele testemunha por aquilo que é impossível dizer, ou seja, ele fala logicamente por aquela que não pode articular-se desse modo: a loucura, a perda da razão. E em nome dela adquire validade. O testemunho válido, compreensível, sobrevivente à perda da razão, torna-se inautêntico por não conseguir falar na língua da loucura absoluta (dela nada racional sobreviveria).

Relaciona-se aqui sobrevivência de pessoas e experiência radical da morte com a sobrevivência de um discurso lógico com a experiência radical da loucura absoluta. Ou seja, vida e logos. Mas a sociedade moderna adota o paradigma bio-político do estado de exceção, do fazer viver e deixar morrer. E o abandono do louco, do louco infrator, como já demonstrado, é uma estratégia que visa conferir sanidade ao bando, dando uma "coesão racional". O estado de exceção excepciona a loucura, o que vale dizer que o poder soberano é logocêntrico. O extermínio de judeus nos campos foi uma atitude racional, assim como é racional a internação do louco infrator nos HCTPs.

A decisão consciente, que leva em conta o saber, a norma e a razão, que se esforça em esgotar todas as informações necessárias à realização da justiça, precisa sempre interromper esse esforço para poder dizer-se. É que há uma urgência intrínseca à justiça. Ela não dispõe de todo o tempo e de todos os saberes para ser dita. Pelo contrário, a decisão "justa" deve ser a mais rápida possível, imediata.

\footnotetext{
E mesmo que ela dispusesse de tudo isso, mesmo que ela se desse tempo, todo o tempo e todos os saberes necessários a esse respeito, pois bem, o momento da decisão, como tal, aquele que deve ser justo, precisa sempre um momento finito de urgência e de precipitação; ele não deve ser a consequência ou o efeito daquele saber teórico ou histórico, daquela reflexão ou daquela deliberação, já que a decisão marca sempre a interrupção da deliberação jurídico - ou ético - ou político-cognitiva que a precede, e que deve precedê-la. O instante da decisão é uma loucura, diz Kierkegaard (DERRIDA, 2007, p. 51).
}

Acreditar que a decisão ou a ação estão calcadas firmemente na razão, apresenta-se como uma loucura. A decisão, no seu instante, é louca, ainda que deva ser precedida da deliberação. Razão e loucura passam a conviver pela própria estrutura da decisão. E esse princípio serve para a decisão judicial que aplica a medida de segurança, internando o louco infrator no HCTP, mas também serve ao sujeito, a todo sujeito que age. O momento da ação, apesar de toda a deliberação que possa ou deva precedê-lo, é o momento de um salto na noite da desrazão. Essa precipitação mostra que o sujeito 
moderno, cognoscente e consciente de seus atos e da norma (ninguém se escusa de cumprir a lei, alegando que não a conhece) age loucamente, pelo inevitável de sua condição humana. Os caminhos da razão conduzem ao desfiladeiro, mas o salto é uma loucura. E é por isso que a justiça não tem um limite, uma lei ou um código ético (normativo) que a dimensione. Para Derrida (2007, p. 54) ela tem um porvir e "este pede a abertura, a vinda do outro (que vem) sem o qual não há justiça". A decisão justa é louca, ela é a abertura ao outro, ao porvir, ao acontecimento que excede os cálculos e antecipações. A decisão justa é aquela que se abre ao impossível.

É justamente sobre a racionalidade, ao logocentrismo dessa medida que tenta assegurar um corpo saudável ao bando, que o testemunho do louco infrator pode aplicar um golpe. Um testemunho que se aproxima da loucura que a vive e sobrevive a ela, mas que ao mesmo tempo seja válido, necessário, torna-se uma baliza para uma reescritura da ética. Não uma ética normativa, que determina ou sugere comportamentos, mas uma ética do acolhimento, da nãoexclusão do relato, do dever de testemunhar ainda que o testemunho só seja possível àqueles que não podem fazê-lo.

Acolher o testemunho do louco infrator é questionar o discurso jurídico e o psiquiátrico e a internação nos HCTP - mais: a existência dessas instituições. E é questionar o logocentrismo que exclui a possibilidade desse testemunho e instala o binarismo loucura versus sanidade. O testemunho do louco é (im)possível e é em nome dessa impossibilidade possível, em nome daqueles que não podem mais dizer, é que ele deve ser acolhido. Oportunidade ética de fazer o múltiplo, de implodir binarismos e sedimentações, de propor a acolhida do Zeugnis, de tentar escutar o não-dito.

A emergência e o lugar de destaque dado a tal testemunho, totalmente desprovido da possibilidade de enunciar verdades, fazem sombra nos outros discursos dominantes, difere seu estabelecimento. Tentar retirar os discursos de sua supremacia, inserindo o testemunho daquele que é louco e infrator, auxilia na ampliação da série de discursos, torna os conceitos de loucura infração e periculosidade indecidíveis e, consequentemente, possibilita sentidos complexos costurados nos rastros deixados pela série. Um desafio político contra a essencialização dessas categorias e a estabilização transcendente das identidades. A abolição da medida de segurança e o respeito às singularidades ainda assujeitadas a tal instrumento jurídico-psiquiátrico depende da capacidade de tornar instáveis esses discursos dominantes.

Testemunho (im)possível. Ao estar mais ou menos articulado ao logos, permite o seu acesso (entendimento, compreensão), e se assim se apresentar, já não é o testemunho exclusivo da desrazão, da loucura - já é outro que também envolve o logos. E ainda, porque 
não há crença numa verdade a ser acessada pelo testemunho, pela experiência. Mas, por outro lado, formando uma aporia, faz-se necessário esse testemunho (im)possível sobre o impensável, porém vivido. A ética, no sentido de abrigo, morada, e não de adesão ou de estudo da norma, exige isto, que esse testemunho (discurso) seja acolhido. Trata-se de não excluir ninguém do relato e de lidar com o testemunho necessário.

\section{Referências}

AGAMBEN, G. Homor sacer: o poder soberano e a vida nua I. Belo Horizonte: Editora da UFMG, 2007.

O que resta de Auschwitz: o arquivo e a testemunha. São Paulo: Boitempo, 2008.

ARENDT, H. Origens do totalitarismo. São Paulo: Companhia das Letras, 1989.

BARROS, D. D. Cidadania versus periculosidade social: a desinstitucionalização como desconstrução do saber. In: AMARANTE, P. (Org.). Psiquiatria social e reforma psiquiátrica. Rio de Janeiro: Fiocruz, 1994, p. 171 - 193.

BENJAMIN, W. Magia e técnica, arte e política: ensaios sobre literatura e história da cultura. 7. ed. São Paulo: Brasiliense, 1994.

BRASIL. Lei no 7.209, de 11 de julho de 1984. Altera dispositivos do Decreto-Lei $n^{\circ} 2.848$, de 7 de dezembro de 1940 - Código Penal, e dá outras providências. Diário Oficial da União, Brasília, DF. Disponível em: <http://www. planalto.gov.br/CCIVI L/leis/19801988/L7209.htm>. Acesso em: 26 mar. 2009.

Constituição (1988). Constituição da República Federativa do Brasil. Brasília, DF: Senado Federal, 2004.

. Lei no 10.216, de 06 de abril de 2001. Dispõe sobre a proteção e os direitos das pessoas portadoras de transtornos mentais e redireciona o modelo assistencial em saúde mental. Diário Oficial da União, Brasília, DF, p. 2, 09 abr. 2001. Disponível em: < http://www.saude.sc.gov.br/geral/planos/programas_e_projetos/sau de_mental/lei 10216. htm>. Acesso em: $16 \mathrm{mar} .2009$.

Ministério da Saúde/Ministério da Justiça. Seminário Nacional para Reorientação dos Hospitais de Custódia e Tratamento Psiquiátrico: Relatório Final. Brasília, 2002.

CARRARA, S. Crime e loucura: o aparecimento do manicômio judiciário na passagem do século. Rio de Janeiro: EdUERJ; São Paulo: EdUSP, 1998.

DERRIDA, J. Posições. Belo Horizonte: Autêntica, 2001.

FOUCAULT, M. A verdade e as formas jurídicas. Rio de Janeiro: Nau, 1996. 
Rìo de J aneiro: Jorge Zahar, 1997.

História da sexualidade 1: a vontade de saber. 13. ed. Rio de J aneiro: Edições Graal, 1999.

Vigiar e punir: o nascimento da prisão. 15. ed. Petrópolis:

Vozes, 2002.

GOFFMAN, E. Manicômios, prisões e conventos. 7. ed. São Paulo: Perspectiva, 2005.

PERES, M. F. T.; NERY FILHO, A. A doença mental no direito penal brasileiro: inimputabilidade, irresponsabilidade, periculosidade e medida de segurança. História, Ciências, Saúde, Manguinhos, Rio de Janeiro, v. 9, n. 2, maio/ago. 2002. Disponível em: <http://direitoeprocessopenal.blogspot.com/ >. Acesso em: 22 mar. 2009.

SCOTT, J. Experiência. In: SILVA, A. L.; LAGO, M. C. S.; RAMOS, T. R. O. Falas de gênero. Florianópolis: Ed. Mulheres, 1999, p. 21-55.

SELIGMANN-SILVA, M. "Zeugnis" e "Testimonio": um caso de intraduzibilidade entre conceitos. Letras no 22: Literatura e Autoritarismo, Santa Maria, n. 22, jan./jun. 2001. Disponível em: <http://w3.ufsm.br/revistaletras/artigos_r22/11_marcio_silva.pdf. >. Acesso em: 24 de maio de 2010.

\section{Endereço para correspondência}

Marcele de Freitas Emerim

Departamento de Psicologia - UFSC - Campus Universitário Trindade - Caixa Postal 47688.040-900 - Florianópolis - SC - Universidade Federal de Santa Catarina.

Endereço eletrônico: marceleemerim@yahoo.com.br

Mériti de Souza

Departamento de Psicologia - UFSC - Campus Universitário Trindade - Caixa Postal 47688.040-900 - Florianópolis - SC - Universidade Federal de Santa Catarina.

Tel: (48) 3238-9319

Endereço eletrônico: meritisouza@yahoo.com.br

Recebido em: 21/07/2011

Reformulado em: 28/09/2011

Aceito para publicação em: 29/09/2011

Acompanhamento do processo editorial: Alexandra Cleopatre Tsallis

\section{Notas}

* Psicóloga. Mestranda no Programa de Pós-Graduação em Psicologia da UFSC Universidade Federal de Santa Catarina.

**Doutora em Psicologia Clínica - PUC-SP. Pós Doutorado no CES - Centro de Estudos Sociais - da Universidade de Coimbra. Professora no Programa de PósGraduação em Psicologia da Universidade Federal de Santa Catarina. 